\title{
DIMENSIÓN DEMOCRÁTICA Y DELIBERATIVA DEL PROCESO JUDICIAL DE INTERÉS PÚBLICO
}

\author{
DIMENSÃO DEMOCRÁTICA E DELIBERATIVA DO PROCESSO JUDICIAL \\ DE INTERESSE PÚBLICO
}

\author{
María Carlota Ucín ${ }^{\mathrm{I}}(\mathbb{D}$
}

\footnotetext{
I Universidad de Palermo, Adjunta ordinaria (por concurso) de Derecho Procesal Civil en la Facultad de Cs. Jurídicas y Sociales de la UNLP, Buenos Aires, Argentina.

Doctora en Derecho. E-mail: carlota.ucin@gmail.com
}

\begin{abstract}
Resumen: En el presente trabajo me focalizo en el análisis de la dimensión democrática y deliberativa del proceso judicial, asumiendo que su perfeccionamiento puede servir para legitimar procedimentalmente la intervención de los jueces en los litigios de Interés Público, caracterizados por un planteamiento en clave constitucional de conflictos de índole estructural.
\end{abstract}

Palabras Clave: Litigio de Interés Público. Proceso judicial. Democracia deliberativa.

Abstract: No presente trabalho, concentro-me na análise da dimensão democrática e deliberativa do processo judicial, assumindo que seu aprimoramento possa servir para legitimar processualmente a intervenção de juízes em litígios de interesse público, caracterizados por uma abordagem constitucional de conflitos de leis de natureza estrutural.

Keywords: Litígios de Interesse Público. Processo judicial. Democracia deliberativa.

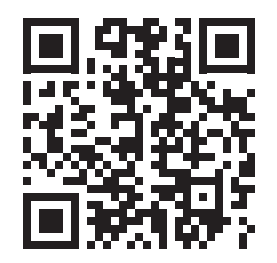

DOI: http://dx.doi. org/10.31512/rdj.v20i37.55

Autora convidada 


\section{Introducción}

Existe, tanto en Latinoamérica cuanto en algunos países de Europa central y oriental pero también de África, una práctica relativamente generalizada de litigios, guiados por el Interés Público, cuyo común denominador parece ser la hipótesis de que es posible provocar alguna medida de cambio social a través del litigio.

Así, estos conflictos ponen en discusión políticas públicas a la luz de los valores constitucionales, procurando la vigencia de los derechos fundamentales. Esta forma de llevar discusiones de corte social a los tribunales, como una forma de activismo político, ha cobrado especial fuerza en aquellos países donde el margen de desigualdad social es más acuciante y ha tendido a poner sobre el tablero problemas estructurales de pobreza y exclusión social.

Desde este entendimiento, se podría ver al proceso judicial como un "microcosmos democrático" del Estado de Derecho, con connotaciones de libertad, igualdad y participación, a través del contradictorio, en un clima de legalidad y responsabilidad. ${ }^{1}$ Así, se puede asumir que la propiedad deliberativa de la Democracia debe ser transversal a todos los poderes del Estado, siendo un modo de gobernar y hacer política, dando razones públicamente de las decisiones que se adoptan e incorporando, en la mayor medida de lo posible, la voz de los diversos sectores afectados.

Por esto, asumo que en que los procesos judiciales de tipo colectivo orientados por el Interés Público se impone la adecuada participación de los afectados fomentando la racionalidad comunicativa que propicie el entendimiento de los participantes. Esta forma de enriquecer al proceso, con elementos deliberativos, permite pensar en la legitimidad de un tratamiento judicial de cuestiones impregnadas de un gran contenido político.

De este modo, asegurando la participación deliberativa de los afectados en el marco del proceso, se puede mejorar su calidad epistémica, contribuyendo a la mayor racionalidad de las decisiones judiciales. Ello sin perjuicio de la consideración de la reforzada exigencia de justificación de las decisiones judiciales en este tipo de procesos, para lo que se muestra de gran utilidad el esquema proporcionado por el "principio de proporcionalidad". 2

En línea con ello, podríamos preguntamos, puntualmente, por qué antes de adoptar una decisión sobre un conflicto social, de alcances estructurales y que involucra

1 Dinamarco, Cândido R., A instrumentalidade do processo, Editora Revista dos Tribunais, São Paulo, Brasil, 1987 , p. 26.

2 En el mismo sentido, se ha dicho que para ser compatible con la teoría del discurso en el marco de una democracia discursiva o deliberativa, el control de constitucionalidad debe tener también un carácter discursivo. Y el control de constitucionalidad tendrá tal carácter, si la interpretación de la Constitución y de los derechos en ella contenidos puede ser concebida como un discurso, relacionado con el discurso democrático general, de manera tal que, permita que los ideales discursivos se realicen en una mayor medida de lo que sería el caso mediante la operación del discurso democrático por sí solo. Alexy, Robert, Teoría del discurso y derechos constitucionales, Fontamara, México, 2005, p. 60. 
la revisión de políticas públicas, sería necesario un proceso de amplia participación y deliberación. Téngase presente que el modelo al que esto se contrapone sería el de un paradigma procesal individual tal como hoy lo conocemos, en el cual, las partes - solo dos - presentan ante el juez sus argumentos. Pero resulta en definitiva éste, quien tiene la última palabra para dirimir la cuestión y fijar la conducta debida en una sentencia.

Este modelo, adecuado a la resolución de conflictos de derecho privado, donde se trata de decir el Derecho para el caso particular, resulta insuficiente para dar tratamiento al tipo de conflictos derivados del control constitucional de políticas públicas que se ponen en revisión cuando se reclaman derechos fundamentales. Por ello, en el siguiente apartado se desarrollará el carácter deliberativo del proceso, como uno de los ejes en los que se sustenta la legitimidad del proceso colectivo orientado por el Interés Público.

\section{Dimensión democrática y deliberativa del proceso}

Seguidamente me centraré en aquellas condiciones intrínsecas al proceso que permitirían la construcción de un contexto propicio para el enjuiciamiento de cuestiones de política pública. Se considerarán entonces, en primer lugar, aquellas vinculadas con las posibilidades de concebir al proceso judicial como un espacio abierto a la participación y la deliberación. Este análisis se apoyará en la estructura de los procesos de conocimiento típicos.

Se revisarán cuáles sean las formas posibles de dotar al proceso de mayor participación de los afectados en las diversas etapas del mismo. Así como también, las formas necesarias para permitir que dicha intervención se vea guiada por una racionalidad comunicativa, ${ }^{3}$ tendiente a lograr el entendimiento. Esta última impronta argumentativa también se hará presente al momento de revisar el contenido de la decisión judicial.

Para el señalado análisis se desarrollará a continuación, la consideración del proceso como un "contexto discursivo" en los términos de la Teoría de la Argumentación Jurídica. Luego, considerando su división en dos grandes etapas, se tratarán las fases

3 La "racionalidad comunicativa" - ubicada en el mismo plano que la racionalidad epistémica y teleológica - se refiere al uso comunicativo de expresiones lingüísticas que, sin embargo, no puede reconducirse a ninguna de las otras dos. Con cada "acto de habla" su emisor persigue el objetivo de entenderse con el oyente sobre algo. Es a este objetivo que Habermas llama "ilocutivo" y del que señala dos niveles: en primer término el acto de habla debe ser entendido por el oyente y luego, en la medida de lo posible aceptado por él. Así, quedan definidos como racionales, aquellos actos de habla comprensibles y respecto de los cuales el hablante puede, en las circunstancias dadas, cargar con una garantía creíble respecto de su contenido, en el sentido que las pretensiones de validez ínsitas en tal acto podrían hacerse efectivas discursivamente. Entonces, determinar si se cumplen las condiciones de validez de las pretensiones involucradas habrá de hacerse discursivamente. Pero como una argumentación en condiciones ideales sería interminable por cuanto, siempre podrían aparecer nuevas informaciones o razones, se puede sugerir que fácticamente se concluye con una argumentación cuando las razones en el horizonte de los supuestos de fondo mantenidos hasta ese momento en forma aproblemática, se adensan hasta tal punto formando un conjunto coherente, que se produce un acuerdo sin coerciones acerca de la aceptabilidad de las pretensiones de validez en litigio Habermas, J. Racionalidad del entendimiento. Aclaraciones al concepto de racionalidad comunicativa desde la Teoría de los actos de habla, en Verdad y justificación, Editorial Trotta, Madrid, 2002, p1 17 y Facticidad y Validez. Sobre el derecho y el Estado democrático de derecho en términos de teoría del discurso, $4^{\circ}$ Edición, Trotta, Madrid, 2005; p 298. 
componentes de la "etapa de conocimiento", en la que se lleva a cabo el control de constitucionalidad o convencionalidad de la política pública (o su omisión) a la luz de los estándares constitucionales o convencionales.

Esto importa considerar adecuadamente la integración subjetiva de la litis, para permitir que los afectados por el conflicto de trascendencia colectiva, puedan participar deliberativamente en el seno del proceso, delimitando objetivamente el conflicto y contribuyendo a la determinación de los argumentos fácticos y normativos. Esto habrá de repercutir sobre la decisión declarativa de certeza que cierre dicha primera etapa del proceso.

Pero también resulta crucial comprender que dicha decisión, tendrá una carga reforzada de la argumentación, en atención a la naturaleza de las cuestiones "políticas" que se discuten. En particular, porque el Poder Judicial estaría ingresando en dominios prima facie privativos de otros poderes. En razón de esto, se dedicará el último apartado a la revisión de las adecuaciones necesarias en la fundamentación de la decisión judicial.

Por razones de espacio, dejo fuera del presente análisis la consideración de la segunda etapa del proceso, la que persigue la implementación del cambio social para adecuar la realidad a las mandas constitucionales y convencionales. Esta etapa también debe mantener una impronta participativa y deliberativa, pues resulta ésta la base necesaria para la construcción de soluciones legítimas y adecuadas a la índole de los conflictos en revisión.

\section{La participación discursiva en la etapa de conocimiento: las audiencias como espacio deliberativo}

A los fines de lograr acercar al proceso judicial a los cánones discursivos presentados, es necesario complementar la adecuada integración de la litis, con la creación de foros específicos en los que se propicie la necesaria deliberación. Se vuelve fundamental, propiciar una intervención guiada por las reglas de la razón antes expuestas.

En particular, el juez debe conducir a las partes hacia formas dialógicas orientadas por la regla general de la fundamentación, imponiendo que las intervenciones tengan una finalidad discursiva guiada al entendimiento y que, a su vez, todos los participantes puedan intervenir en condiciones de igualdad y sin coerciones. ${ }^{4}$ Para ello resulta fundamental la concepción del proceso judicial como un trámite llevado adelante a través de audiencias, donde se pueda estimular dicho diálogo orientado al entendimiento.

4 Esto se condice con las reglas del discurso de Robert Alexy. Véase: Teoría de la argumentación jurídica. La teoría del discurso racional como teoría de la fundamentación jurídica, Centro de Estudios Constitucionales, Madrid, 1997. 
En nuestra experiencia nacional, ${ }^{5}$ las audiencias, generalmente desarrolladas con carácter público, se han mostrado como una herramienta sumamente eficaz a este respecto. Entre los argumentos dados por la propia Corte Suprema al incorporar esta vía de participación, se destacó su importancia a los fines de contribuir al mejoramiento del Estado Constitucional de Derecho, fomentado la participación ciudadana y el control y la publicidad de la administración de justicia. ${ }^{6}$

En esta misma línea se ha expuesto que el compromiso de la justicia con la deliberación podría encauzarse a través de un proceso abierto, colectivo y dialógico, que construya su propia decisión atendiendo a puntos de vista plurales. La creación de ámbitos como las "audiencias públicas" podría ayudar a que los poderes políticos adopten sus decisiones de una manera imparcial a condición, claro, de que los argumentos vertidos en el seno de las mismas fueran tenidos en cuenta en la decisión final. ${ }^{7}$

Conforme la Acordada 30/07 de la CSJN, las audiencias pueden ser entonces de tres tipos: informativa, que tiene por objeto escuchar e interrogar a las partes sobre aspectos del caso a decidir, ordenatoria, cuyo objeto es encauzar el procedimiento a fin de mejorar la tramitación de la causa y conciliatoria, que intenta que las partes alcancen soluciones no adversariales. Estas distintas formas de audiencias tienden a lograr fines diversos, desde la finalidad epistémica, tendiente a un mayor conocimiento de los hechos y argumentos controvertidos en la causa, hasta las audiencias con fines conciliatorios.

Es importante, además, distinguir los fines perseguidos por las audiencias, según cuál sea la etapa procesal en la que se inserten. Es por ello, que conviene abordar separadamente la participación deliberativa de los afectados según se trate de la primera etapa del proceso (cognoscitiva) o la segunda, de implementación de las medidas de cambio social (etapa de ejecución de sentencia).

En esta primera etapa, la participación habrá de tener lugar en la fase de integración de la litis y en la de prueba (primeras dos fases del proceso cognoscitivo). Se tratará entonces prevalentemente de audiencias de tipo informativas e instructorias, tendientes a lograr una adecuada determinación de la litis y una acabada verificación de los hechos controvertidos. ${ }^{8}$ La finalidad claramente epistémica de estas intervenciones resulta una fuente adicional de legitimación para el obrar del poder jurisdiccional.

5 En este sentido, argumentando acerca de las posibilidades argumentativas de un proceso desarrollado a través de audiencias públicas, véase: Verdaguer, Alejandro C., Importancia de las audiencias públicas ante la Corte, Ponencia presentada en el XXII Congreso Nacional de Derecho Procesal, Paraná, Entre Ríos, 2003, Libro de Ponencias, TII, pp 47-56.

6 Véanse los considerandos de la Acordada 30/2007. También puede consultarse: Lorenzetti, Ricardo, Las audiencias públicas y la Corte Suprema, en Por una justicia dialógica. El Poder Judicial como promotor de la deliberación democrática, Gargarella (comp.), Siglo XXI editores, Buenos Aires, 2014, pp 345-354.

7 Véase al respecto: Gargarella, Roberto, Democracia deliberativa, justicia dialógica y derechos sociales, manuscrito no publicado, CONICET, 2006.

8 Si bien nada dice la regulación en cuanto a la oportunidad de las audiencias conciliatorias, cabría pensar que las mismas debieran tener lugar una vez dictada la sentencia declarativa de certeza. La naturaleza de las cuestiones implicadas y el interés público que en ellas gravita, harían pensar que la conciliación no podría recaer sobre los 
La intervención de los afectados, orientados hacia el entendimiento comunicativo, no se agota sin embargo en esta primera etapa, como es posible imaginar. Luego del pronunciamiento declarativo de certeza que habrá de concluir la primera etapa del proceso, será fundamental que se mantenga dicha lógica participativa en la fase de implementación del cambio social.

La consideración de la voz de los afectados en esta última etapa también resulta fundamento de la legitimidad del obrar del Poder Judicial y de las soluciones que se adopten. Su finalidad también será epistémica en punto a poder conocer la voz de los afectados en relación con la implementación de las medidas. Sin embargo, resulta plausible pensar que esta etapa, también será viable la celebración de audiencias conciliatorias. ${ }^{9}$

Lo que se debe procurar en este tipo de procesos no es reproducir en escala colectiva la lógica individual. No se trata de sustituir a los sujetos individuales por sujetos colectivos, replicando así la dinámica del proceso tradicional. En cambio, se debe modificar la lógica de aquél para adecuarla a los requerimientos discursivos y de mayor participación. Es decir, diseñar un proceso que persiga la construcción de soluciones políticas legítimas que operen cambios concretos en diversos niveles institucionales. En este sentido, conviene subrayar que el instituto de las audiencias públicas sólo cuenta con esta reglamentación interna dada por la Corte Suprema para los casos planteados ante sí. Se impone la regulación legal de procesos especiales para el trámite de los litigios guiados por el Interés Público que incluyan, en particular, este instituto.

Sugiero entonces, que tales reformas deben ser encauzadas a partir de los métodos discursivos antes expuestos, guiados hacia el entendimiento constructivo de soluciones. De esta forma, y tal vez sólo de ésta, puede lograrse la legitimidad del Poder Judicial, como seno en el cual se puedan debatir las cuestiones de índole política y colectiva. ${ }^{10}$ Pienso que tales adecuaciones procedimentales, realizadas al interior del proceso judicial, pueden ser coadyuvantes de otras formas de diálogo e interacción entre poderes, que tiendan a lograr la legitimidad del control judicial de constitucionalidad, en particular, ante la cuestionada falta de vigencia de los derechos fundamentales.

En relación con la legitimidad de esta clase de litigio, se ha dicho que no se requiere que los tribunales tengan la única palabra y ni siquiera la última. Sólo requiere que a los jueces les sea posible hablar con una autoridad cuya medida es el proceso. El derecho del juez de hablar y de los demás de escuchar dependen justamente de la

alcances de los derechos pero en cambio sí, sobre las modalidades de ejecución de la condena. En todo caso, parece plausible pensar que en la fase de implementación, las audiencias podrán tener esta naturaleza.

9 En principio no sería razonable la introducción de audiencias conciliatorias en la primera etapa del proceso (cognoscitiva) porque la naturaleza del conflicto que se discute, impregnada por el Interés Público, no debería admitir acuerdos transaccionales. Cosa distinta sucede en la etapa de implementación, donde lo que se puede "negociar" son formas de cumplimiento y no la sustancia de los derechos involucrados.

10 En el mismo sentido, André Rufino do Vale, Argumentação jurídica e legitimidade democrática da Jurisdição Constitucional, Revista de Interés Público (REDIP), Año 1, n.1, p. 38-58. 
calidad del proceso mediante el cual se actúa, de su habilidad para desprenderse y adoptar distancia frente a los litigantes y el cuerpo político, de su capacidad de prestar toda su atención a las pretensiones elevadas por las partes y de responder a ellas con juicios que trasciendan la meras preferencias y fundamenten una sentencia de valor constitucional. ${ }^{11}$

De hecho, el Juez ejerce su poder después de haber participado en un diálogo acerca del significado de los valores públicos. Lo que distingue este espacio de otros espacios de deliberación institucional es que en el caso del proceso judicial, el juez no controla su agenda, como así tampoco puede evadir la obligación de dar respuesta a través de una sentencia que resuelva el caso planteado. ${ }^{12}$

Pero además de esto, el juez debe ser el garante de un diálogo plural, en el que se vean representados los intereses de todos los posibles afectados. Éstos están obligados a escuchar y hablar, en especial de cierta manera. ${ }^{13}$ En el apartado siguiente se habrá de hacer referencia a este último aspecto, a partir de una revisión del deber de fundamentación.

\section{La decisión judicial como corolario de un debido proceso argumentativo}

Sin perjuicio entonces de todo lo dicho en relación con el carácter discursivo del proceso, para lo cual resulta fundamental el carácter deliberativo de la participación de los afectados en el debate judicial, también es importante señalar el rol que le cabe al juez en dicho diálogo. Entonces, cabe indagar en cuáles han de ser sus funciones discursivas específicas. A partir de esto, y como segundo eje estructurante del proceso colectivo que aquí se propone, se debe señalar el necesario reforzamiento del deber de justificación de las decisiones judiciales.

Este elemento se orienta a la determinación y demostración de la corrección de aquellas decisiones que operen un control sobre las políticas públicas. Concretamente, se trata de considerar cuál deba ser la manera en que haya de dirimir en términos argumentativos el conflicto policéntrico ${ }^{14}$ y colectivo que se ha expuesto ante sí. El tipo de cuestiones que emergen de la judicialización de los conflictos de Interés Público en general, impone la revisión de cuestiones de índole política y esto permite anticipar una suerte de regla de la carga de la fundamentación de las decisiones judiciales que prescribiera que: "A mayor injerencia en cuestiones prima facie políticas, mayor carga de la argumentación”.

La consideración de los derechos fundamentales como mandatos de optimización parece ser una forma de permitir un control de la proporcionalidad (ponderación) de las

11 Fiss, Owen, Los fundamentos sociales y politicos de la adjudicación, en El Derecho como razón pública, Marcial Pons, Madrid, 2007, p 84.

12 Ibidem, 333

13 Ibidem, p 36.

14 Fuller, Lon L., The forms and limits of Adjudication, Harvard Law Review, Vo. 92, No 2 (1978), pp 353-409. 
medidas de gobierno a partir de un esquema que asegure un recorrido argumental que abastezca la fundamentación adecuada de las decisiones judiciales. ${ }^{15}$

Pero además, resulta fundamental contar con estándares normativos que faciliten a los jueces la interpretación de los alcances de los derechos así como también, herramientas de medición que les permitan luego la evaluación del cumplimiento de tales obligaciones constitucionales de parte de los otros poderes. Todo ello, al clarificar las obligaciones asumidas por el Estado en materia de derechos sociales, permite adicionalmente el ejercicio del control de parte de la ciudadanía de la vigencia de éstos.

El desarrollo de este tópico resulta fundamental para la justificación concreta del obrar de los jueces en áreas de aplicación del Derecho que antes le resultaban ajenas. Este control de constitucionalidad, les viene impuesto a su vez, por el proceso de constitucionalización de los ordenamientos jurídicos, del que nuestro país no está exento. Por ello, si lo que se quiere es legitimar dicha intervención, también se habrá de trabajar sobre este punto.

\section{Conclusiones propositivas}

1. El tipo de control de constitucionalidad (y convencionalidad) que viene impuesto por el estadio de evolución de nuestros ordenamientos abre un nuevo campo de intervención judicial que requiere ser repensado en términos de su legitimidad democrática;

2. Sin perjuicio de las discusiones teóricas respecto del problema del carácter contrayamoritario del Poder Judicial, existe un margen de legitimación procedimental que viene determinado por la posibilidad de constituir al proceso judicial como un espacio democrático y deliberativo;

3. La intervención de los afectados por conflictos de índole estructural en el contexto de audiencias guiadas por una racionalidad comunicativa (guiada al entendimiento) fija las bases epistémicas para una adecuada solución del conflicto;

4. La reforzada "carga de la argumentación" de las decisiones judiciales en cuestiones que se vinculan con la revisión de políticas públicas, resulta una herramienta adecuada para el control de la actividad de los jueces que intervienen en estas cuestiones;

5. El principio de proporcionalidad (ponderación) resulta un esquema argumental propicio para la evaluación de la razonabilidad de las cuestiones de índole política sometidas a la decisión jurisdiccional;

15 Remito a lo dicho en: Ucín, M.C.: Las instrucciones de aplicación del Código Civil y Comercial. Un análisis interpretativo del artículo $3^{\circ}$, Revista Electrónica Derecho y Ciencias Sociales, No 15, (Octubre 2016) y La demostración de la razonabilidad, en la obra colectiva: Los Principios Procesales, Roberto O. Berizonce Coordinador, Librería Editora Platense, 2011. 
6. La participación y deliberación de los afectados, no debería ceñirse a las etapas anteriores, sino que también debería tener especial importancia en la etapa de ejecución de la decisión judicial, en un largo proceso de cambio estructural.

\section{Referencias}

Alexy, Robert, Teoría de la argumentación jurídica. La teoría del discurso racional como teoría de la fundamentación jurídica, Centro de Estudios Constitucionales, Madrid, 1997 ;

Alexy, Robert, Teoría del discurso y derechos constitucionales, Fontamara, México, 2005;

Dinamarco, Cândido R., A instrumentalidade do processo, Editora Revista dos Tribunais, São Paulo, Brasil, 1987;

Fiss, Owen, Los fundamentos sociales y politicos de la adjudicación, en El Derecho como razón pública, Marcial Pons, Madrid, 2007;

Fuller, Lon L., The forms and limits of Adjudication, Harvard Law Review, Vo. 92, N 2 (1978), pp 353-409.

Gargarella, Roberto, Democracia deliberativa, justicia dialógica y derechos sociales, manuscrito no publicado, CONICET, 2006;

Habermas, Jürgen, Facticidad y Validez. Sobre el derecho y el Estado democrático de derecho en términos de teoría del discurso, $4^{\circ}$ Edición, Trotta, Madrid, 2005;

Habermas, Jürgen, Racionalidad del entendimiento. Aclaraciones al concepto de racionalidad comunicativa desde la Teoría de los actos de habla, en Verdad y justificación, Editorial Trotta, Madrid, 2002;

Lorenzetti, Ricardo, Las audiencias públicas y la Corte Suprema, en Por una justicia dialógica. El Poder Judicial como promotor de la deliberación democrática, Gargarella (comp.), Siglo XXI editores, Buenos Aires, 2014, pp 345-354;

Rufino do Vale, André, Argumentação jurídica e legitimidade democrática da Jurisdição Constitucional, Revista de Interés Público (REDIP), Año 1 Nº, pp38-58;

Ucín, María Carlota, La demostración de la razonabilidad, en la obra colectiva: Los Principios Procesales, Roberto O. Berizonce Coordinador, Librería Editora Platense, 2011.

Ucín, María Carlota, Las instrucciones de aplicación del Código Civil y Comercial. Un análisis interpretativo del artículo $3^{\circ}$, Revista Electrónica Derecho y Ciencias Sociales, No 15, (Octubre 2016); 
Verdaguer, Alejandro C., Importancia de las audiencias públicas ante la Corte, Ponencia presentada en el XXII Congreso Nacional de Derecho Procesal, Paraná, Entre Ríos, 2003, Libro de Ponencias, TII, pp 47-56. 